\title{
Membaca Makna Iklan Politik Pilpres 2019
}

\author{
Sumbo Tinarbuko \\ Prodi Desain Komunikasi Visual, Jurusan Desain, \\ Fakultas Seni Rupa dan Program Pascasarjana ISI Yogyakarta \\ Jalan Parangtritis KM. 6,5 Sewon Bantul, Daerah Istimewa Yogyakarta
}

sumbotinarbuko@gmail.com

Tulisan ini dibuat untuk membaca interaksi makna tanda verbal dan pesan verbal serta tanda visual dan pesan visual dari desain iklan politik pemilihan calon presiden dan calon wakil presiden dalam Pilpres 2019. Bagi produsen tanda yang terdiri dari desainer komunikasi visual, mempelajari semiotika komunikasi visual untuk memahami tanda, kode dan makna konotasi desain iklan politik Pilpres 2019 menjadi sangat penting. Dengan demikian, produsen tanda akan lebih kreatif dalam menciptakan tanda verbal dan tanda visual serta pesan verbal dan pesan visual. Tulisan ini dibuat menggunakan metode penelitian kualitatif dengan mendeskripsikan dan menginterpretasikan makna konotasi desain iklan politik Pilpres 2019 berdasarkan bangunan teori semiotika, teori desain komunikasi visual, teori gaya bahasa dan teori komunikasi politik. Metode analisis semiotika komunikasi visual ditawarkan dan dimanfaatkan sebagai metode analisis tanda verbal dan tanda visual serta pesan verbal dan pesan visual. Proses analisis objek penelitian dilakukan dengan memanfaatkan konsep analisis Triadik Sumbo Tinarbuko. Konsep analisis Triadik Sumbo Tinarbuko penulis ciptakan untuk mengidentifikasikan, mendeskripsikan dan memahami makna tanda verbal dan tanda visual serta pesan verbal dan pesan visual yang terkandung dalam desain iklan politik Pilpres 2019.

Kata kunci: iklan politik pilpres 2019, semiotika komunikasi visual, triadik sumbo tinarbuko.

\section{Reading the Meaning of 2019 Presidential Election Political Advertisement}

This paper was made to read the interaction of the meaning of verbal signs and verbal messages as well as visual signs and visual messages from the design of political advertisements for the election of presidential candidates and vice presidential candidates in the 2019 Presidential Election. For producers of signs that consist of visual communication designers, is very important that communication of visual communication semiotics to allow signs, codes and connotation meanings to design political ads for the 2019 Presidential Election. Thus, sign manufacturers will be more creative in making verbal signs and visual signs and verbal messages also visual messages. This paper was made using qualitative research methods by describing and interpreting the connotation meaning of the political advertising design of the 2019 Presidential Election based on semiotic theory, visual communication design theory, language style theory and political communication theory. Methods of visual communication semiotics offered and used as a method of analyzing verbal signs and visual signs and verbal messages also visual messages. The process of object analysis was carried out by utilizing the Triadik Sumbo Tinarbuko concept. The author's concept of Triadic Sumbo Tinarbuko analysis was created to identify, describe and understand the meaning of verbal signs and visual signs and verbal messages and visual messages that contained in the design of the 2019 Presidential Election political ads.

Keywords: 2019 presidential election political ads, visual communication semiotics, triadik sumbo tinarbuko.

Proses Review : 1 - 18 April 2019, Dinyatakan Lolos: 22 April 2019 


\section{PENDAHULUAN}

Iklan politik Pilpres 2019 tabiatnya hampir sama dengan iklan komersial (Nuradi, 1996:4). Keberadaannya merupakan bagian dari fenomena bisnis modern. Tidak ada perusahaan (baca: partai politik) yang ingin maju dan memenangkan kompetisi bisnis (baca: Pilpres 2019) tanpa mengandalkan iklan (politik). Demikian pentingnya peran iklan politik dalam bisnis kontestasi kampanye Pemilu 2019, sehingga salah satu parameter bonafiditas partai politik dan calon presiden terletak pada seberapa banyak dana yang digelontorkan untuk iklan politik tersebut. Di samping itu, iklan politik merupakan wajah cantik dari sebuah partai politik dan calon presiden. Ia sanggup menghubungkan partai politik dan calon presiden dengan calon pemilih (Tinarbuko, 2009:1).

Bagi calon presiden dan calon wakil presiden, mitos beriklan politik berbiaya mahal, diyakini mendongkrak popularitas. Namun, popularitas sang calon tidak memengaruhi elektabilitas. Bagi pemilih, hal penting adalah kerja nyata. Bukan tampang, citra, apalagi sekadar nama tenar. Iklan politik Pilpres 2019, apa pun bentuknya, hanyalah upaya memperkenalkan diri kepada masyarakat luas.

Iklan politik Pilpres 2019 dengan memajang wajah sang calon penguasa mengindikasikan si pengiklan tidak merakyat. Mereka tidak mengutamakan ideologi. Mereka bagaikan peserta kontes kecantikan dan lomba ketampanan. Bukan ideologi, hanya sebatas kontesnologi.

Jika sang calon penguasa terjun ke jagat politik dan ingin dikenal publiknya, dia harus mau bekerja keras. Hasil kerja kerasnya akan mengangkat namanya kelak. Tentu saja kerja keras itu bukan dalam hitungan bulan atau setahun sebelum pemilihan umum. Mereka sudah harus mulai bekerja sejak sekarang untuk Pemilu 10 tahun mendatang.

Realitas sosial menyatat fakta, cara promosi paling efektif adalah dari mulut ke mulut. Meski demikian, beriklan penting, karena beriklan sama dengan berinvestasi. Sebaliknya, beriklan tidak sama dengan cara kerja petani yang menanam padi lantas 3-4 bulan kemudian panen. Beriklan terutama iklan politik seperti menanam pohon jati. Lama dan perlu dirawat dengan sepenuh hati.

Atas dasar pengalaman komprehensif semacam itu, rakyat cenderung waspada. Rakyat semakin jeli menentukan siapa yang layak memimpin negeri ini. Kehati-hatian seperti itu didasari fakta sejarah. Selama ini, para pemimpin bangsa yang diberi kepercayaan rakyat untuk mengelola Republik tercinta dikenal lewat kemasannya saja. Karena senantiasa mendewakan kemasan visualnya akibatnya, para pemimpin bangsa dan pejabat publik lebih banyak bekerja dengan beradu strategi demi merebut kekuasaan. Dengan label penguasa, mereka dipastikan memiliki hak mengelola bangsa dan negara ini. Lewat predikat pen- guasa, mereka mempunyai hak dan merasa paling mampu serta paling benar mengatur bangsa ini. Dengan sebutan penguasa, mereka dapat memproyeksikan dirinya beserta pengikutnya untuk menikmati kesejahteraan lahir batin.

Dalam era budaya layar seperti sekarang ini, masyarakat tidak akan terpengaruh janji calon presiden dan calon wakil presiden yang manis di mulut, namun pahit dalam kenyataan kehidupan sehari-hari. Mereka tidak mau bagian dari kehidupannya diganggu oleh janji gombal yang disuarakan calon presiden dan calon wakil presiden dengan dukungan partai politik tertentu yang senang berburu kekuasaan.

Untuk itulah, kita berharap kepada calon presiden dan calon wakil presiden dan partai politik untuk senantiasa mengedepankan moralitas, menjunjung tinggi kejujuran, dan berpolatindak pada kearifan lokal serta tidak menebar sampah visual iklan politik saat berkampanye. Kita percaya, masih banyak partai politik serta calon presiden dan calon wakil presiden yang layak mendapatkan pulung amanat rakyat menjadi pemimpin bangsa. Dengan menempuh jalan yang baik dan benar serta bermartabat. Kita percaya, masih banyak negarawan pengayom masyarakat, yang rela mengabdikan diri demi kesejahteraan seluruh rakyat Indonesia.

Berdasarkan hal tersebut di atas, tulisan berjudul Membaca Makna Iklan Politik Pilpres 2019 dihadirkan dengan tujuan utama untuk memahami makna konotasi atas keberadaan tanda verbal dan tanda visual serta pesan verbal dan pesan visual yang muncul dalam iklan politik Pilpres 2019.

Tulisan ini berfokus memahami makna konotasi pada iklan politik Pilpres 2019 dengan mengambil objek pembahasan berupa iklan politik Pilpres 2019 yang dimuat pada harian Kompas terbitan tanggal 26 Maret 2019.

Ada dua iklan politik Pilpres 2019. Pertama, iklan politik milik Ir. H. Joko Widodo (calon presiden petahana) berpasangan dengan calon wakil presiden Prof. Dr. (H.C.) KH. Ma'aruf Amin. Jokowi dan Amin memperoleh nomor undian 01 sebagai penanda visual nomor coblosan. Sedangkan penantangnya, pasangan calon presiden Prabowo Subianto dengan Sandiaga Uno yang memosisikan diri sebagai calon wakil presiden. Prabowo dan Sandi mendapatkan nomor undian 02 sebagai penanda visual nomor coblosan.

Tulisan berjudul Membaca Makna Iklan Politik Pilpres 2019 dibuat menggunakan metode penelitian kualitatif dengan mendeskripsikan dan menginterpretasikan makna konotasi iklan politik Pilpres 2019 berdasarkan bangunan teori semiotika (Barthes, 2010), (Danesi, 2010), (Eco, 1979), (Judith, 1984) (Noth, 1995), teori desain komunikasi visual (Tinarbuko, 2015), (Tinarbuko, 2017), teori gaya 
bahasa (Keraf, 2005) dan teori komunikasi politik (Nimmo, 1993). Metode analisis semiotika komunikasi visual dimanfaatkan sebagai metode analisis tanda verbal dan tanda visual serta pesan verbal dan pesan visual. Proses analisis objek penelitian dilakukan dengan memanfaatkan konsep analisis Triadik Sumbo Tinarbuko (Tinarbuko, 2017).

Hasil tulisan ini diharapkan dapat memberikan kontribusi positif berupa rujukan secara teoretis kepada produsen tanda yang terdiri dari desainer komunikasi visual. Hal itu menjadi sangat penting. Oleh karena itu, mereka diharapkan berkenan mempelajari semiotika komunikasi visual. Tujuannya untuk memahami tanda, kode dan makna konotasi iklan politik Pilpres 2019. Harapan lainnya, produsen tanda akan lebih kreatif dalam menciptakan tanda verbal dan tanda visual. Begitu pula saat merancang pesan verbal dan pesan visual yang diterapkan dalam desain iklan politik di tahun politik ini.

\section{METODE PENELITIAN}

Metode analisis semiotika komunikasi visual pada tanda verbal dan tanda visual desain iklan politik Pilpres 2019, sejatinya beroperasi pada dua jenjang analisis. Pertama, analisis tanda secara individual, mencakup: tanda, kode, dan makna tanda. Kedua, analisis tanda yang membentuk teks. Sedangkan teks menurut Yasraf Amir Piliang (1998:88) dipahami sebagai kombinasi tanda-tanda. Dengan demikian, karya desain komunikasi visual salah satunya berbentuk desain iklan politik juga dapat dilihat sebagai sebuah teks.

Tulisan ini menggunakan metode penelitian kualitatif dengan cara mengidentifikasikan dan menginterpretasikan makna konotasi iklan politik Pilpres 2019. Semuanya dilakukan dengan menyandarkan diri pada bangunan teori semiotika, teori desain komunikasi visual, teori gaya bahasa dan teori komunikasi politik. Cara melakukan proses analisis objek penelitian dilakukan secara deskriptif dengan memanfaatkan konsep Triadik Sumbo Tinarbuko.

Konsep ini penulis ciptakan untuk mengidentifikasikan dan memahami makna konotasi atas tanda dan kode pada karya desain komunikasi visual berbentuk iklan politik Pilpres 2019.

Di sisi lain, iklan politik Pilpres 2019 membutuhkan media untuk merepresentasikan pesan verbal dan pesan visual yang ada di dalamnya. Untuk itu, dipilihlah media berbentuk koran atau biasa juga disebut sebagai media massa cetak.

Keberadaan iklan politik Pilpres 2019, diselaraskan dengan target khalayak sasaran yang dituju. Garis lurus anta-

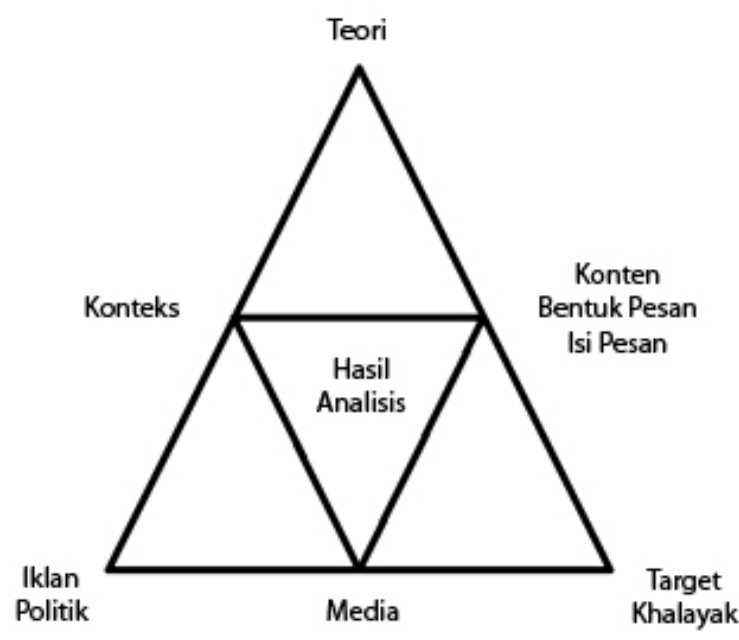

\section{Triadik Sumbo Tinarbuko}

ra karya desain komunikasi visual berbentuk iklan politik Pilpres 2019 dengan pilihan media media berwujud harian Kompas, penempatannya selajur dengan sudut target khalayak sasaran. Ketiganya ditempatkan pada sisi bawah garis Triadik Sumbo Tinarbuko.

Di sisi kiri Triadik Sumbo Tinarbuko terdapat sudut lurus karya desain komunikasi visual berbentuk iklan politik Pipres 2019 adalah konteks (kesepakatan proses mengkaji karya iklan politik Pilpres 2019, dalam bentuk rumusan masalah). Dan sudut paling atas adalah teori utama dan teori penunjang yang digunakan sebagai referensi untuk membantu mengkaji objek pembahasan tersebut.

Di sisi sebelah kanan garis Triadik Sumbo Tinarbuko dimulai dari sudut target khalayak sasaran, lalu naik ke sudut konten (berisi bentuk pesan dan isi pesan iklan politik Pilpres 2019,) dan di sudut atas ketemu lagi dengan sudut adalah teori utama dan teori penunjang yang digunakan sebagai referensi untuk membantu mengkaji objek pembahasan tersebut.

Singgungan antara sisi kiri garis Triadik Sumbo Tinarbuko bernama konteks akan terhubung garis lurus dengan singgungan sisi kanan bernama konten. Selanjutnya menurun menghubungkan dengan sudut dari singgungan karya desain komunikasi visual berwujud iklan politik Pilpres 2019, dengan khalayak sasaran yang bernama media. Ketiga titik tersebut (konteks - konten - media) membentuk segitiga sama sisi terbalik. Pada titik itulah alur pikir kajian semiotika komunikasi visual menemukan bentuknya berupa paparan deskrisptif makna konotasi tanda verbal dan tanda visual serta pesan verbal dan pesan visual iklan politik Pilpres 2019, yang menjadi objek pembahasan tulisan ini (Tinarbuko, 2017:55-56). 


\section{ANALISIS DAN INTEPRETASI DATA}

\section{Identifikasi serta Deskripsi Tanda Verbal dan Tanda Visual Iklan Politik Pilpres 2019 versi Jokowi Amin 01 Indonesia Maju}

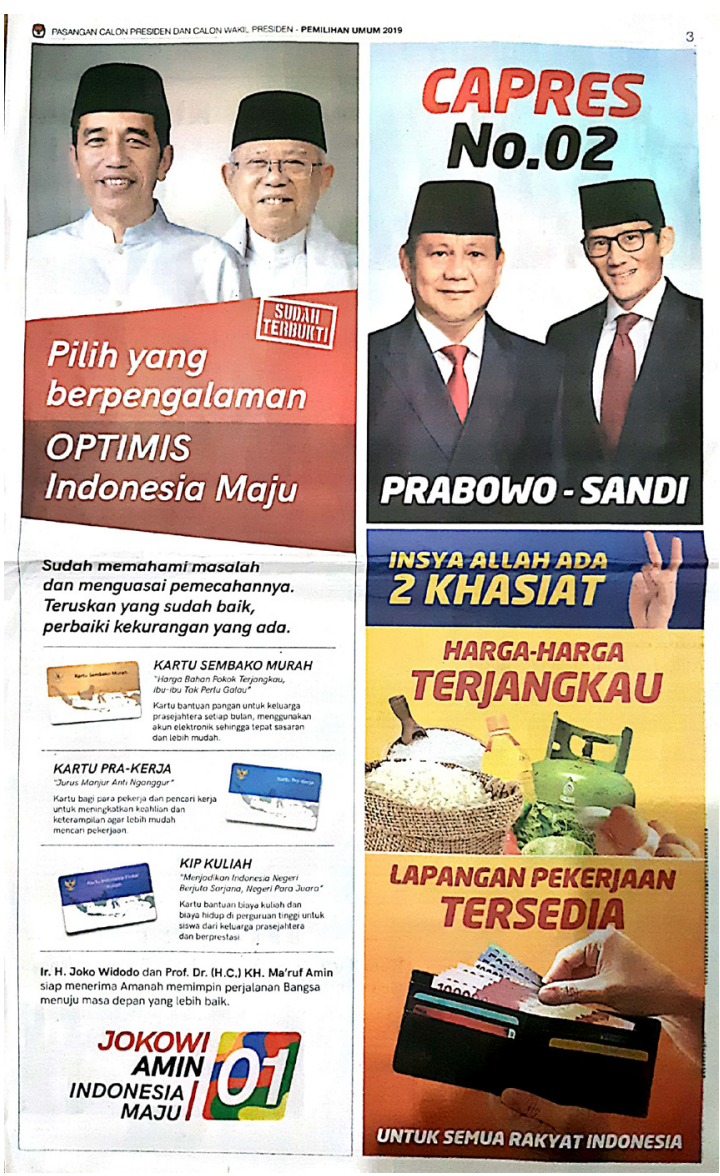

(Iklan politik Jokowi - Amin 01, berukuran $16 \mathrm{~cm}$ x 53,5 cm dan iklan politik Prabowo - Sandi 02, berukuran $16 \mathrm{~cm}$ x 53,5 $\mathrm{cm}$, dimuat di harian Kompas, halaman 3, tanggal 26 Maret 2019)

\section{Tanda Verbal:}

Headline:

Pilih yang Berpengalaman

Sub Headline:

OPTIMIS Indonesia Maju

Tagline:

\section{SUDAH TERBUKTI}

Body Copy:

Sudah memahami masalah dan menguasai pemecahannya. Teruskan yang sudah baik, perbaiki kekurangan yang ada.

\section{KARTU SEMBAKO MURAH}

'Harga Bahan Pokok Terjangkau, Ibu-Ibu Tak Perlu Galau"
Kartu bantuan pangan untuk keluarga prasejahtera setiap bulan, menggunakan akun elektronik sehingga tepat sasaran dan lebih mudah.

\section{KARTU PRA-KERJA}

"Jurus Manjur Anti Nganggur"

Kartu bagi para pekerja dan pencari kerja untuk meningkatkan keahlian dan keterampilan agar lebih mudah mencari pekerjaan.

\section{KIP KULIAH}

"Menjadikan Indonesia Negeri Berjuta Sarjana, Negeri Para Juara"

Kartu bantuan biaya kuliah dan biaya hidup di perguruan tinggi untuk siswa dari keluarga prasejahtera dan berprestasi.

\section{Closer:}

Ir. H. Joko Widodo dan Prof. Dr. (H.C.) KH. Ma'ruf Amin Siap menerima Amanah memimpin perjalanan Bangsa menuju masa depan yang lebih baik.

JOKO AMIN 01 INDONESIA MAJU

\section{Tanda Visual:}

Penampakan visual ikon wajah Jokowi, calon presiden petahana nomor urut 01, diletakkan di sebelah kiri taferil iklan politik Pilpres 2019. Di sisi kanan agak ke belakang, terpampang ikon wajah KH. Ma'ruf Amin, calon wakil presiden. Mereka ditampilkan dalam posisi tegap dengan senyum mengembang di bibirnya. Mereka mengenakan baju koko. KH. Ma'ruf Amin menambahkan slempang kain putih sebagai penanda visual seorang ulama. Ikon wajah KH. Ma'ruf Amin, calon wakil presiden tampak memakai kacamata dan mengenakan kopiah warna hitam. Tampak pula rambut putih di sekitar kopiahnya. Sedangkan ikon wajah Jokowi sebagai calon presiden petahana juga memakai topi kopiah warna hitam. Rambut Jokowi masih tampak hitam legam. Kedua wajah kedua ikon pasangan Jokowi - Amin menghadap pembaca harian Kompas, tempat iklan politik tersebut dipasang.

Ikon wajah pasangan calon presiden nomor 01 Jokowi Amin disatukan dalam dua buah garis tebal diagonal yang ujung akhirnya dalam posisi lebih tinggi. Dua buah garis tebal diagonal itu masing-masing diberi warna berbeda. Garis diagonal pertama yang secara visual menutup setengah badan calon presiden nomor 01 berwarna merah segar. Pada garis lapis kedua diberi warna coklat bata.

Di atas dua garis tebal itu diterakan headline dan slogan. Di dalam headline dituliskan kalimat yang berbunyi: Pilih yang Berpengalaman. OPTIMIS Indonesia Maju. Sedangkan slogan ditulis dengan huruf kapital yang diberi garis tebal di sekelilingnya: SUDAH TERBUKTI.

Sedangkan pada bagian tengah, diterakan body copy yang berisi program kerja calon presiden nomor 01. Di antara- 
nya: Kartu Sembako Murah (warna kuning emas dan putih dengan ilustrasi ikon peta Indonesia dan ikon Burung Garuda), Kartu Pra-Kerja (warna biru muda dan putih dengan ilustrasi ikon peta Indonesia dan ikon Burung Garuda), KIP Kuliah (warna biru tua dan putih dengan ilustrasi ikon peta Indonesia dan ikon Burung Garuda)

Pada bagian paling bawah dari iklan capres 01, diletakkan closer bertuliskan: Ir. H. Joko Widodo dan Prof. Dr. (H.C.) KH. Ma'ruf Amin. Siap menerima Amanah memimpin perjalanan Bangsa menuju masa depan yang lebih baik. JOKO AMIN 01 INDONESIA MAJU. Pada angka 01 yang diberi warna putih dibatasi empat garis berbentuk empat persegi panjang dengan ukuran $3,5 \mathrm{~cm}$ x 4,5 cm. Di dalamnya terdapat bentuk garis non geometris berjumlah enam dengan warna hijau muda, hijau tua, , merah, biru tua, kuning dan hijau muda. Sedangkan tipografi Jokowi diberi warna merah. Tipografi Amin diberi warna hitam. Demikian pula Indonesia Maju, juga diberi warna hitam.

\section{Analisis Semiotika Komunikasi Visual pada Iklan Poli-} tik Pilpres 2019 versi Jokowi Amin 01 Indonesia Maju Secara konotatif, pesan verbal yang muncul dari tanda verbal iklan politik Pilpres 2019 versi Jokowi - Amin adalah untaian janji politik untuk melanjutkan program kerja yang sudah dijalankan presiden petahana selama 4,5 tahun. Hal itu terlihat dari Headline yang berbunyi: Pilih yang Berpengalaman. Diperkuat dengan hadirnya Sub Headline yang berbunyi: OPTIMIS Indonesia Maju. Dan dikunci dengan pernyataan politik berdasarkan pengalaman kerja Jokowi. Hal itu terpampang dengan jelas pada body copy iklan politik capres milik Jokowi - Amin yang berbunyi: 'Sudah memahami masalah dan menguasai pemecahannya. Teruskan yang sudah baik, perbaiki kekurangan yang ada".

Makna konotasi yang muncul dari headline iklan politik ini, ketika seseorang memilih sesuatu, ia harus teliti sebelum membeli. Peribahasa klasik mengajarkan kita untuk jangan membeli kucung dalam karung. Artinya, calon pemilih harus meneliti dan mencari bukti rekam jejak calon presiden yang akan dipilihnya. Atas dasar makna konotasi tersebut, headline iklan politik milik capres Jokowi - Amin menjadi sangat kuat pesan komunikasi politiknya. Penguatan makna konotasi tersebut terlihat pada sub headline yang berbunyi, 'OPTIMIS Indonesia Maju”. Kalimat ini memiliki konotasi memupus kekhawatiran calon pemilih atas propaganda dan kampanye hitam yang menyatakan Indonesia akan bubar dan berbagai pernyataan pesimis lainnya yang dilontarkan kubu sebelah, yakni capres pasangan Prabowo - Sandi.

Makna konotasi yang dimunculkan body copy iklan politik capres milik Jokowi - Amin yang berbunyi: 'Sudah memahami masalah dan menguasai pemecahannya. Teruskan yang sudah baik, perbaiki kekurangan yang ada". Sejatinya ingin menegaskan headline dan sub headline yang menyatakan: pilihlah calon presiden yang memiliki pengalaman dalam bidangnya. Sebab presiden yang berpengalaman akan membawa bangsa Indonesia menjadi Negara yang maju.

Diksi ‘berpengalaman' memiliki makna konotasi yang meluas dan melebar. Jokowi terbukti memiliki pengalaman dalam bidang pemerintahan. Hal itu dibuktikan sejak dia menjabat sebagai Walikota Surakarta, kemudian Gubernur DKI Jakarta serta dilanjutkan menjadi Presiden terpilih. Pengalaman dalam bidang pemerintahan yang dipahami secara konotatif sebagai pengalaman komprehensif yang didapatkan saat menjadi kepala pelayanan masyarakat dari tingkat kotamadya, propinsi hingga presiden.

Makna konotatif berpengalamannya Jokowi semakin dikuatkan oleh pengalaman religiusitas dari calon wakil presiden nomor urut 01 Prof. Dr. (H.C.) KH. Ma'ruf Amin. Sebagai seorang kyai sepuh, Amin memiliki banyak pengalaman religiusitas sejak dia dinobatkan sebagai seorang kyai.

Kombinasi dua pengalaman yang senantiasa menebar energi kebaikan, optimis, kerja keras dan energi religiusitas ini mengekalkan makna konotasi pasangan Jokowi-Amin sebagai calon presiden yang optimis, berpengalaman, memahami masalah dan mampu mencari jalan keluar sekaligus pemecahan masalahnya.

Pemecahan masalah yang ditawarkan capres 01 pasangan Jokowi - Amin, secara konkrit dapat dilihat pada body copy iklan politik milik mereka. Ada tiga solusi yang ditawarkan untuk mengatasi masalah ekonomi dan sosial budaya yang melanda bangsa Indonesia. Yakni: 1) KARTU SEMBAKO MURAH 'Harga Bahan Pokok Terjangkau, Ibu-Ibu Tak Perlu Galau'. Kartu bantuan pangan untuk keluarga prasejahtera setiap bulan, menggunakan akun elektronik sehingga tepat sasaran dan lebih mudah. 2) KARTU PRA-KERJA 'Jurus Manjur Anti Nganggur" Kartu bagi para pekerja dan pencari kerja untuk meningkatkan keahlian dan keterampilan agar lebih mudah mencari pekerjaan. 3) KIP KULIAH 'Menjadikan Indonesia Negeri Berjuta Sarjana, Negeri Para Juara" Kartu bantuan biaya kuliah dan biaya hidup di perguruan tinggi untuk siswa dari keluarga prasejahtera dan berprestasi.

Makna konotasi atas body copy iklan politik milik capres 01 Jokowi - Amin yang sejatinya berisi program kerja mereka menjamin warga masyarakat untuk kenyang perutnya, kenyang pikirannya dan kenyang nalar perasaannya. Makna konotasi dari program kerja Jokowi - Amin mengindikasikan adanya keseimbangan antara kondisi fisik dengan nalar perasaan dan akal pikiran dari warga masyarakat yang diayomi dan diayeminya (dibuat ayem hati, perasaan dan pikirannya). Dari sana akan muncul optimisme untuk berkarya nyata sesuai dengan talenta masing-masing. 
Sementara itu, closer dari iklan politik milik capres nomor urut 01 berbunyi: Ir. H. Joko Widodo dan Prof. Dr. (H.C.) KH. Ma'ruf Amin Siap menerima Amanah memimpin perjalanan Bangsa menuju masa depan yang lebih baik. JOKO AMIN 01 INDONESIA MAJU. Makna konotasi yang muncul dari closer adalah Jokowi ingin menuntaskan program kerjanya yang semula terfokus pada pembangunan infrastruktur untuk kemudian dilanjutkan pada pembangunan sumber daya manusia agar Indonesia maju.

Makna konotasi untuk terwujudnya Indonesia maju, terbaca dari hadirnya Jokowi - Amin dalam ajang kontestasi Pilpres 2019. Capres nomor urut 01 hadir dengan dukungan penuh dari partai koalisi yang simbol warnanya terpampang dalam empat garis berbentuk empat persegi panjang dengan ukuran 3,5 cm x 4,5 cm. Di dalamnya terdapat bentuk garis non geometris berjumlah enam dengan warna hijau muda, hijau tua, , merah, biru tua, kuning dan hijau muda.

Makna konotasi pada angka 01 yang merupakan nomor urut capres Jokowi - Amin dapat dipahami sebagai sesuatu yang sudah pasti baik dan terbukti. Angka 1 adalah representasi angka yang akan menambahkan manakala direkatkan dengan simbol matematika penambahan. Artinya, untuk menuju Indoensia maju harus selalu ditambahkan dengan karakter yang kuat serta potensi diri yang sanggup berkembang dalam segala medan perjuangan. Sedangkan angka 1 saat direkatkan dalam simbol matematika perkalian, memiliki makna tetap. Maknanya, untuk menjadi Indonesia satu segenap rakyat Indonesia harus memiliki ketetapan hati dan memiliki sikap optimis secara nasional untuk tetap menjaga kesatuan Negara Indonesia. Untuk tetap menuntukkan jati diri bangsa Indonesia sebagai Negara yang berdasarkan Pancasila dan UUD 1945.

Gaya bahasa yang digunakan dalam iklan politik capres 01 Jokowi - Amin dipilih menggunakan gaya bahasa tidak resmi dan gaya bahasa repetisi. Menurut Gorys Keraf (2005:118), gaya bahasa tak resmi banyak digunakan untuk kepentingan tidak resmi dan hadir dalam bentuk yang tidak konservatif. Sedangkan gaya bahasa repetisi, menurut Gorys Keraf (2005:127) adalah pengulangan bunyi, suku kata, kata atau bagian kalimat yang dianggap penting untuk memberi tekanan dalam konteks yang sesuai.

Gaya bahasa gaya bahasa tidak resmi dan gaya bahasa repetisi pada iklan politik capres nomor urut 01 terlihat pada Headline, Sub Headline, Tagline, Body Copy. Sedangkan gaya bahasa repetisi terlihat pada body copy: 1) KARTU SEMBAKO MURAH ''Harga Bahan Pokok Terjangkau, Ibu-Ibu Tak Perlu Galau”. 2) KARTU PRA-KERJA 'Jurus Manjur Anti Nganggur'. 3) KIP KULIAH ' Menjadikan Indonesia Negeri Berjuta Sarjana, Negeri Para Juara”.
Identifikasi serta Deskripsi Tanda Verbal dan Tanda Visual Iklan Politik Pilpres 2019, versi Prabowo - Sandi 02

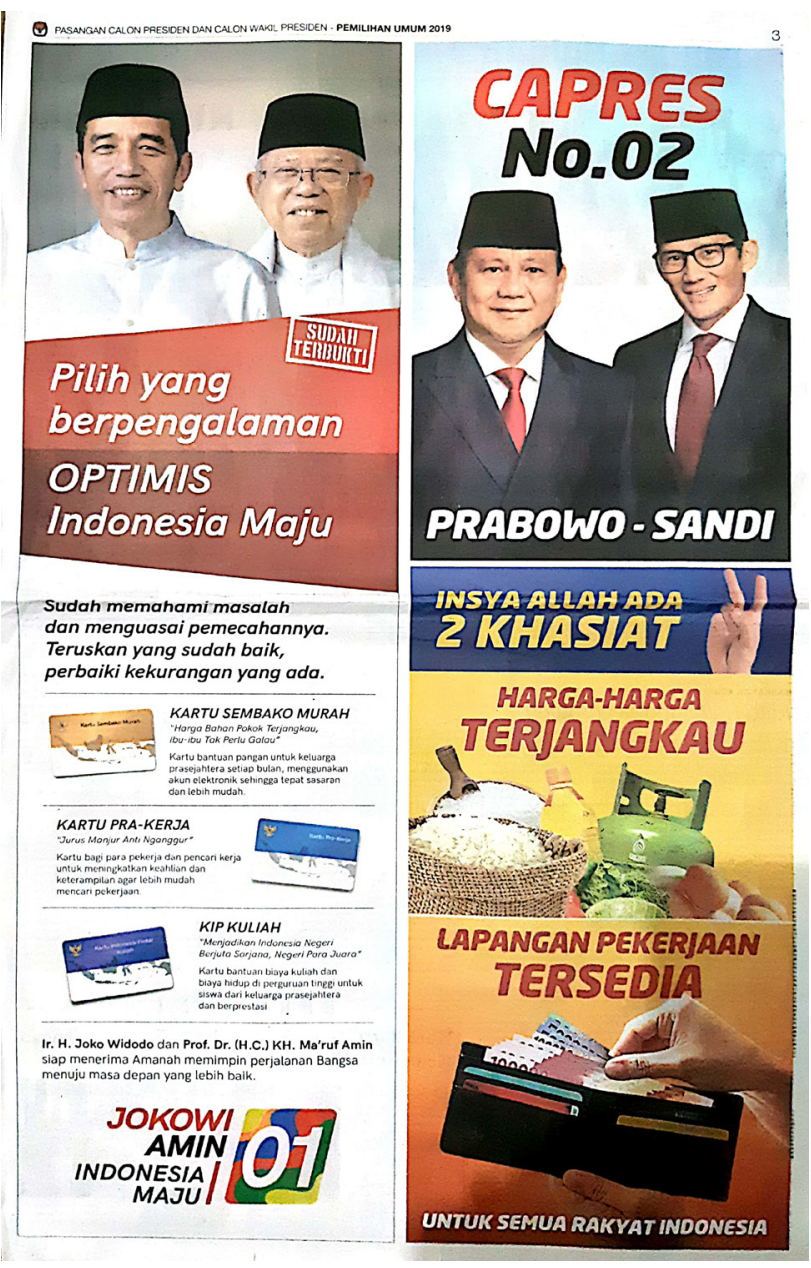

(Iklan politik Jokowi - Amin 01, berukuran $16 \mathrm{~cm}$ x 53,5 cm dan iklan politik Prabowo - Sandi 02, berukuran $16 \mathrm{~cm}$ x 53,5 $\mathrm{cm}$, dimuat di harian Kompas, halaman 3, tanggal 26 Maret 2019)

Tanda Verbal:

Headline:

CAPRES No. 2

PRABOWO - SANDI

Sub Headline:

INSYA ALLAH ADA 2 KHASIAT

Body Copy:

HARGA-HARGA TERJANGKAU

LAPANGAN PEKERJAAN TERSEDIA

Tagline:

UNTUK SEMUA RAKYAT INDONESIA

Tanda Visual:

Ikon wajah Prabowo Subianto dengan senyum simpul ber- 
sanding dengan ikon wajah Sandiaga Uno yang memakai kacamata sambil melemparkan senyum lebar hingga terlihat deretan giginya bagian atas.

Mereka berdua mengenakan jas berwarna hitam dengan baju putih dan dasi merah. Jas yang dipakai Prabowo bukaannya sebatas dada. Sedangkan jas yang dikenakan Sandi bukaannya sampai perut. Mereka berdua juga menggunakan kopiah. Kedua wajah kedua ikon pasangan Prabowo - Sandi menghadap pembaca harian Kompas, tempat iklan politik tersebut dipasang.

Tata visual dari iklan politik Pilpres 2019 versi Prabowo - Sandi terbagi menjadi tiga bagian. Bagian pertama dan bagian ketiga ditampilkan dalam bidang empat persegi panjang dengan ukuran yang hampir sama.

Bagian pertama berukuran $16 \mathrm{~cm}$ x 23,5 cm. Menampilkan ikon wajah pasangan Prabowo - Sandi. Di atas ikon capres nomor urut 02 diterakan headline: Capres No. 2 dan di bawahnya dibubuhkan teks: Prabowo - Sandi.

Sedangkan bagian kedua dari iklan politik Pilpres 2019 milik pasangan capres Prabowo - Sandi diberi biru, berukuran $16 \mathrm{~cm}$ x $5 \mathrm{~cm}$. Di dalam bidang tersebut direkatkan teks berbunyi: INSYA ALLAH ADA 2 KHASIAT. Di sisi sebelah kanan teks tersebut diletakkan ikon tangan kanan yang sedang mengangkat jari telunjuk dan dari tengah secara bersamaan. Pada sisi lain dari ikon tangan kanan itu juga menampilkan penampakan visual jari manis, kelingking dan jempol yang dilipat secara bersamaan.

Bagian ketiga berdimensi $16 \mathrm{~cm}$ x 25,5 cm. Keduanya diberi warna kuning bergradasi oranye menuju warna merah. Pada bagian ketiga dari iklan politik capres Prabowo - Sandi dibagi lagi menjadi dua bagian saya besar. Pada bagian pertama dengan teks warna merah: HARGA-HARGA TERJANGKAU, direkatkan ikon bahan kebutuhan pokok: beras, gula, minyak, sayur mayor, telur dan tabung gas melon. Pada bidang bagian kedua, diberi warna gradi kuning menuju oranye dan berakhir pada warna merah. Bagian atas dari bidang itu direkatkan teks berbunyi: LAPANGAN PEKERJAAN TERSEDIA. Di bawah teks itu dilengkapi ikon sepasang tangan seorang pria yang memegang dompet hitam dalam kondisi terbuka. Di dalam dompet itu terlihat empat kartu pembayaran. Terlihat pula tujuh lembar uang pecahan Rp. 100.000 berwarna merah. Kemudian dua lembar uang pecahan Rp. 50.000 berwarna biru dan satu lembar uang pecahan Rp. 20.000. Bagian paling bawah dari bidang itu diletakkan teks berbunyi: UNTUK SEMUA RAKYAT INDONESIA.

Analisis Semiotika Komunikasi Visual pada Iklan Politik Pilpres 2019 versi Prabowo - Sandi

Secara konotatif, pesan verbal yang muncul dari tanda verbal iklan politik Pilpres 2019 versi Prabowo - Sandi adalah upaya untuk merebut kursi kekuasaan sebagai Presiden
Republik Indonesia dari sang petahana Joko Widodo. Sebagai penantang pasangan Prabowo - Sandi menembakkan dua janji politik yang mereka terakan dalam sub headline yang bertuliskan: INSYA ALLAH ADA 2 KHASIAT.

Makna konotasi yang tersembul dari sub headline yang bertuliskan: INSYA ALLAH ADA 2 KHASIAT adalah atas kehendak Allah, capres Prabowo - Sandi membawa obat yang mampu menyembuhkan kondisi masyarakat yang sedang tertimpa bawah penyakit sosial. Prabowo Sandi memberikan dua obat yang memiliki khasiat hebat untuk menyembuhkan rasa sakit yang diderita warga masyarakat. Obat pertama yang berkhasiat menjamin harga sembako terjangkau. Sedangkan obat kedua berkhasiat menjamin ketersediaan lapangan pekerjaan.

Pada titik ini, iklan politik capres Prabowo - Sandi sedang memosisikan warga masyarakat sebagai makhluk sosial yang berpikiran instan. Secara konotatif mereka berdua sedang mengalami halusinasi sindrom Sinterklas dan Superman.

Makna konotasi sindrom Sinterklas dan Superman yang sedang dialami capres Prabowo - Sandi menunjukkan realitas sosial yang menyatakan mereka berdua merasa mampu dan sanggup menyelesaikan permasalahan ekonomi dan sosial budaya yang membelit bangsa Indonesia. Kemampuan dan kesanggupan Prabowo - Sandi menyelesai berbagai permasalahan disebabkan mereka berdua memiliki obat generik yang mujarab. Obat generik itu mereka yakini memiliki dua khasiat sekaligus. Yakni khasiat pertama berupa jaminan harga sembako terjangkau. Sedangkan khasiat kedua menjamin ketersediaan lapangan pekerjaan.

Diksi 'TERJANGKAU' menurut Kamus Besar Bahasa Indonesia Online (https://kbbi.web.id/jangkau) dituliskan sebagai: 1) tercapai, 2) terbeli atau terbayar. Serta diksi 'TERSEDIA' menurut https://www.kamusbesar.com/ tersedia diartikan sebagai (sudah) disediakan; sudah ada; disediakan untuk.

Dalam konteks iklan politik Pilpres 2019 versi Prabowo Sandi obat generik yang memiliki khasiat menjamin harga sembako terjangkau dan menjamin tersedianya lapangan pekerjaan, secara konotatif menjanjikan sekaligus menjamin semua kebutuhan sembako dapat dibeli oleh warga masyarakat dengan harga terjangkau serta tersedianya lapangan pekerjaan. Sementara itu, secara konotatif makna diksi 'TERJANGKAU' adalah sesuatu yang masih bersifat abstrak. Demikian juga diksi 'TERSEDIA'

Diksi 'TERJANGKAU' memiliki makna konotatif bentangan varian harga yang tidak memiliki nilai ukur secara kuantitatif. Diksi 'TERJANGKAU' juga memiliki makna konotasi yang bersifat abstrak seiring dengan pertanyaan: terjangkau oleh siapa? Apa yang disediakan? Siapakah yang mampu menjangkau harga-harga sembako seperti 
yang dipaparkan dalam iklan politik capres milik Prabowo - Sandi? Bagaimana cara Prabowo - Sandi mewujudkan secara konkrit diksi 'TERJANGKAU' dalam konteks harga sembako? Bagaimana pula cara menyediakan lapangan pekerjaan yang mereka janjikan telah tersedia.

Sementara itu, makna konotasi yang muncul atas ikon wajah Prabowo - Sandi terlihat dari cara tersebut dari kedua pasangan capres nomor urut 02. Senyum simpul Prabowo mengandung makna konotasi sebagai orang yang memendam rasa kecewa. Hal itu terkait erat dengan jejak digital riwayat hidupnya sebagai seorang militer yang gagal menyandang jendral empat bintang. Kemudian kegagalannya dalam membina rumah tangga. Berikutnya Prabowo berkali-kali gagal mendapatkan suara yang sah dalam pemilihan presiden. Di sisi lainnya, senyum lebar Sandiaga Uno hingga menunjukkan deretan gigi bagian atas, memiliki makna konotasi sebagai pribadi yang ambisius untuk meraih jabatan tertinggi dengan segala cara yang ia miliki. Gestur tubuh Sandiaga Uno dalam posisi sedikit miring serta telihat melampau pundak sang jendral, memiliki makna konotasi, Sandi berusaha menguasai dan mengendalikan Prabowo. Hal itu terlihat dari jejak digital Sandi yang memiliki anggaran kampanye lebih besar dari Prabowo. Demikian juga ide program kerja sektor ekonomi dengan mengedepankan konsep Oke Oce. Ser agaya kampanye yang mencoba merangkul kaum milenial sebagai target sasaran utama calon pemilih.

Makna konotasi headline CAPRES No. 2 PRABOWO - SANDI secara kasatmata menjukkan kasta atau posisi yang dinomorduakan. Semacam ban serep dari calon presiden nomor urut 01. Teks CAPRES diberi warna merah, secara konotasi dimaknai sebagai upaya berani dari Prabowo - Sandi menantang presiden petahana yang mengusung tagline: SUDAH TERBUKTI yang ditambilkan dengan warna putih dan disusun dalam susunan huruf capital. Sedangkan teks No.02, yang dibaca sebagai nomor urut kosong dua memiliki makna konotasi adanya nomor dua tentu setelah munculnya nomor satu. Dengan demikian, secara struktural, nomor dua harus rela hadir belakangan menunggu kehadiran nomor satu.

Sementara itu jika dimasukkan dalam konteks hubungan kekerabatan, makna anak nomer dua selalu mengacu dan bercermin dari kakak nomor satu. Maka pasangan Prabowo - Sandi selalu mengacu dan bercermin dari pasangan capres nomor urut 01 . Hal itu terlihat dari program kerja Prabowo Sandi yang meliputi jaminan harga sembako terjangkau terlihat mirip dengan program kerja Jokowi - Amin pada program kerja yang terangkum dalam KARTU SEMBAKO MURAH.

Pada program kerja Prabowo - Sandi yang menjanjikan tersedianya lapangan pekerjaan ternyata maknanya sama sebangun dengan program kerja Jokowi - Amin yang terangkum dalam KARTU PRA-KERJA. Pada kartu tersebut, Jokowi - Amin membeberkan jurus manjur anti nganggur. Kartu tersebut didedikasikan bagi para pekerja dan pencari kerja untuk meningkatkan keahlian dan ketrampilan agar lebih mudah mencari pekerjaan.

Gaya bahasa yang digunakan dalam iklan politik Pilpres 2019 versi Prabowo - Sandi dipilih menggunakan gaya bahasa tidak resmi. Hal itu terlihat pada Sub Headline: INSYA ALLAH ADA 2 KHASIAT. Terlihat pula pada Body Copy: HARGA-HARGA TERJANGKAU. LAPANGAN PEKERJAAN TERSEDIA. Serta terbaca pada Tagline:UNTUK SEMUA RAKYAT INDONESIA

Menurut Gorys Keraf (2005:118-119), gaya bahasa tidak resmi banyak digunakan untuk kepentingan yang bersifat tidak resmi atau tidak formal. 'Menurut sifatnya, gaya bahasa tidak resmi dapat juga memperlihatkan suatu jangka variasi, mulai dari bentuk informal yang paling tinggi hingga gaya bahasa tak resmi yang sudah bertumpang tindih dengan gaya bahasa percakapan kaum terpelajar," tulis Gorys Keraf dalam bukunya berjudul: Diksi dan Gaya Bahasa.

\section{SIMPULAN}

Tulisan ini dibuat dalam rangka melakukan proses pengkajian semiotika komunikasi visual pada iklan politik Pilpres 2019. Proses pengkajian diawali dengan melakukan tahapan identifikasi dan deskripsi atas tanda verbal yang terdiri dari headline, sub headline dan tagline. Proses pengkajian selanjutnya melakukan tahapan identifikasi dan deskripsi atas tanda visual yang terdiri dari: ilustrasi, tipografi, tata visual dan warna dari iklan politik tersebut. Selanjutnya mencari serta memahami makna konotasi atas keberadaan pesan verbal dan pesan visual yang terkandung dalam iklan politik Pilpres 2019.

Penerapan analisis semiotika komunikasi visual dengan objek pembahasan iklan politik Pilpres 2019 ini, melibatkan penggunaan bangunan teori semiotika, teori gaya bahasa, dan teori desain komunikasi visual dan teori komunikasi politik. Semua unsur semiotika yang meliputi tanda, kode, dan makna menjadi pertimbangan utama dalam melihat dan menangkap pesan yang mencuat dalam karya desain komunikasi visual berbentuk iklan politik Pilpres 2019. Penerapan pendekatan analisis semiotika komunikasi visual diharapkan mampu menjadi salah satu pendekatan baru untuk memperoleh makna konotasi atas keberadaan iklan politik Pilpres 2019.

Cara melakukan proses analisis objek penelitian dilakukan secara deskriptif dengan memanfaatkan konsep analisis Triadik Sumbo Tinarbuko. Konsep analisis ini penulis ciptakan untuk melihat dan mengidentifikasikan serta mendeskripsikan tanda verbal dan tanda visual yang terkandung di dalam iklan politik Pilpres 2019. Penerapan konsep analisis Triadik Sumbo Tinarbuko pada ujungnya 
diharapkan mampu memahami makna konotasi atas pesan verbal dan pesan visual yang terkandung dalam iklan politik Pilpres 2019.

Setelah dilakukan proses kajian semiotika komunikasi visual atas objek pembahasan iklan politik Pilpres 2019 dengan menggunakan pendekatan konsep analisis Triadik Sumbo Tinarbuko. Dari sana dapat disimpulkan hubungan ketiga unsur semiotika yang meliputi tanda, kode dan makna terlihat sangat erat keterkaitannya. Interaksi atas tanda verbal dan tanda visual serta pesan verbal dan pesan visual saling melengkapi antara yang satu dengan lainnya. Hasil dari interaksi tersebut kemudian memunculkan makna konotasi sesuai dengan teks dan konteks yang ada di dalam iklan politik Pilpres 2019.

Selain itu, pesan verbal dan pesan visual yang terkandung di dalam iklan politik Pilpres 2019 hadir secara simbolik dan indeksikal. Dengan demikian, hasil penafsiran atas makna konotasi menjadi relatif ideal. Hal itu menyebabkan makna konotasi iklan politik tersebut menjadikan sangat menarik. Mengapa? Karena ketiga unsur semiotika tersebut (tanda, kode dan makna) berhasil menghadirkan pluralitas makna konotasi atas pesan verbal dan pesan visual yang terkandung dalam iklan politik Pilres 2019.

\section{DAFTAR RUJUKAN}

Barthes, Roland (2010). Image/Music/Text atau Imaji Musik Teks, terjemahan Agustinus Hartono (1990). Penerbit Jalasutra, Yogyakarta.

Danesi, Marcel. (2010). Messages, Signs, and Meaning: A Basic Textbook in Semiotics and Communication Theory atau Pesan, Tanda, dan Makna: Buku Teks Dasar Mengenai Semiotika dan Teori Komunikasi, terjemahan Evi Setyarini dan Lusi Lian Piantari (2004). Penerbit Jalasutra, Yogyakarta.

Eco, Umberto. (1979). A Theory of Semiotics. Bloomington: Indiana University Press.

Gorys Keraf (2005). Diksi dan Gaya Bahasa. Jakarta: Penerbit Gramedia Pustaka Utama.

Noth, Winfriend. (1995). Handbook of Semiotics. Blommington and Indianapolis: Indiana University Press.

Nimmo, Dan. (1993). Political Communication and Public Opinion in America atau Komunikasi Politik: Komunikator, Pesan dan Media, terjemahan Tjun Surjaman (buku asli diterbitkan tahun tidak berangka tahun). Penerbit: Remaja Rosdakarya Offset, Bandung.

Nuradi. (1996). Kamus Istilah Periklanan Indonesia. Jakarta: Penerbit PT Gramedia Pustaka Utama.
Piliang, Yasraf Amir. (1998). Sebuah Dunia yang Dilipat, Realitas Kebudayaan menjelang Milenium Ketiga dan Matinya Posmodernisme. Bandung: Penerbit Mizan.

Tinarbuko, Sumbo. (2009). Iklan Politik dalam Realitas Media Yogyakarta: Penerbit Jalasutra.

Tinarbuko, Sumbo. (2009). Semiotika Komunikasi Visual (Edisi Revisi). Yogyakarta: Penerbit Jalasutra.

Tinarbuko, Sumbo. (2015). DEKAVE: Desain Komunikasi Visual Penanda Zaman Masyarakat Global. Yogyakarta: Penerbit CAPS.

Tinarbuko, Sumbo. (2017). Membaca Tanda dan Makna Desain Komunikasi Visual. Yogyakarta: Penerbit BP ISI Yogyakarta.

Williamson, Judith. (1984). Decoding Advertisements, Ideology and Meaning in Advertising. London: Marion Boyars Publishers Ltd, 24 Lacy Road.

\section{Webtografi}

https://kbbi.web.id/jangkau

https:/www.kamusbesar.com/tersedia 